\section{References}

1. Kouchoukos NT, Blackstone EH, Doty DB, et al. Aortic atresia and other forms of hypoplastic left heart physiology. Cardiac Surgery, Vol. 2. New York, NY; Churchill Livingstone; 2003. p. 1377-400.

2. Eidem BW, Cetta F. Unusual finding of cor triatriatum in a newborn with hypoplastic left heart syndrome. J Am Soc Echocardiogr. 2001;14:850-2.
3. Kouchoukos NT, Blackstone EH, Doty DB, et al. Cor triatriatum. Cardiac surgery, Vol. 2. New York, NY; Churchill Livingstone; 2003. p. 781-9.

4. Masui T, Seelos KC, Kersting-Sommerhoff BA, Higgins CB. Abnormalities of the pulmonary veins: evaluation with MR imaging and comparison with cardiac angiography and echocardiography. Radiology. 1991;181:645-9.

\title{
Improved lung perfusion with surgical correction of pulmonary artery sling
}

\author{
Emmanuel Le Bret, MD, PhD, ${ }^{a}$ Brigitte Fauroux, MD, PhD, ${ }^{\mathrm{c}, \mathrm{f}}$ Anne Sigal-Cinqualbre, MD, ${ }^{\mathrm{b}}$ \\ Claire de Labriolle-Vaylet, MD, PhD, ${ }^{\mathrm{d}}$ Alain Batisse, $\mathrm{MD},{ }^{\mathrm{e}}$ Régine Roussin, $\mathrm{MD}$, \\ Emre Belli, MD, and Alain Serraf, MD, PhD, ${ }^{a}$ Le Plessis Robinson and Paris, France
}

I n pulmonary arterial sling (PAS), the left pulmonary artery (LPA) arises from the right pulmonary artery (RPA) and goes leftward between the trachea and the esophagus. This produces a sling around the distal trachea and the proximal bronchi. The LPA thus compresses the superior part of the right bronchus and the distal part of the trachea. Most patients with PAS have clinical symptoms related to tracheal or tracheobronchial compression. When tracheal hypoplasia coexists (ring-sling complex ${ }^{1}$ ), acute episodes of dyspnea and cyanosis are common and may cause major respiratory distress and death. Although the effect of PAS on lung ventilation is well known, the effect of the surgical correction of PAS on left lung perfusion has never been evaluated.

\section{Clinical Summary}

A 5-year-old boy with a history of recurrent pulmonary infections was referred to the pediatric pneumology department.

Preoperative examination. On examination, the patient was an alert and vigorous child weighing $18 \mathrm{~kg}$. Results of clinical examination at rest were normal. A chest radiograph revealed that the left lung was smaller than the right lung, with a minimal shift of the heart and mediastinal structures to the left. Bronchoscopy revealed a mild

From the Département des Cardiopathies Congénitales ${ }^{\mathrm{a}}$ and the Département d'Imagerie Médicale, ${ }^{\text {b }}$ Centre Chirurgical Marie Lannelongue, Université Paris XI, Le Plessis Robinson, France, and the Service de Pneumologie Pédiatrique ${ }^{\mathrm{c}}$ and the Service de Médecine Nucléaire Pédiatrique, ${ }^{\mathrm{d}}$ Hôpital d'Enfants Armand Trousseau, Université Paris VI, Paris, France, and the Unité d'Explorations Cardiologiques, Institut de Puériculture de Paris, ${ }^{\mathrm{e}}$ Paris, France; INSERM UMR-S U 719, ${ }^{\mathrm{f}}$ Paris, France.

Received for publication Sept 6, 2006; accepted for publication Oct 23, 2006.

Address for reprints: Emmanuel Le Bret, $\mathrm{MD}, \mathrm{PhD}$, Département des Cardiopathies Congénitales, Centre Chirurgical Marie Lannelongue, 133 Avenue de la Résistance, 92350 Le Plessis Robinson, France (E-mail: e.lebret@ccml.fr).

J Thorac Cardiovasc Surg 2007;133:815-6

$0022-5223 / \$ 32.00$

Copyright $\odot 2007$ by The American Association for Thoracic Surgery doi:10.1016/j.jtcvs.2006.10.031 compression of the distal trachea by as much as a third of its lumen. A 2-dimensional echocardiogram showed a PAS with a small LPA (7-8 mm) and a large RPA (13-14 mm). A multislice computed tomographic scan confirmed the presence of the PAS and showed the smaller LPA stretched around the trachea (Figure 1).

Ventilation scintigraphy with xenon 133 revealed a mild ventilation asymmetry (55\% for the right lung and $45 \%$ for the left lung), whereas perfusion scintigraphy with albumin, aggregated technetium macro aggregated albumin labeled with Technetium99m (Tc 99m MAA) revealed severe hypoperfusion of the left lung, with a right to left perfusion ratio of $90 \%$ to $10 \%$ (Figure 2, A).

Surgical correction of the vascular malformation was elected to preserve both the perfusion and the function of the left lung.

Operative technique. The operation was performed through a median sternotomy under normothermic cardiopulmonary bypass. The ligamentum arteriosum was divided. The LPA was detached from the RPA, dissected free where it coursed behind the trachea, and translocated to the left side of the trachea. It was then shortened to be implanted to the left side of the main pulmonary artery where the ligamentum arteriosus was inserted. The operative sizing of the pulmonary arteries revealed a mildly hypoplastic LPA relative to the RPA. The anastomosis was performed with continuous 6.0 absorbable monofilament sutures.

Postoperative status. The child was extubated in the operating room. He remained less than 24 hours in the intensive care unit and was discharged from the hospital on the sixth day.

Follow-up. At 5 months, the child was perfectly well, with strictly normal results of clinical examination. According to chest radiography, the left lung remained a little bit smaller than the right one. The perfusion scan showed an increase in the left lung perfusion, with a right to left ratio of $71 \%$ to $29 \%$. At 1 year, the echocardiographic estimate of the LPA diameter remained similar to the preoperative value, but the perfusion scan showed an improvement of the right to left perfusion ratio at $65 \%$ to $35 \%$ (Figure 2, B).

\section{Discussion}

In PAS, left lung perfusion can be dramatically decreased. First, the LPA is usually smaller than the RPA. ${ }^{2}$ Second, the course of 

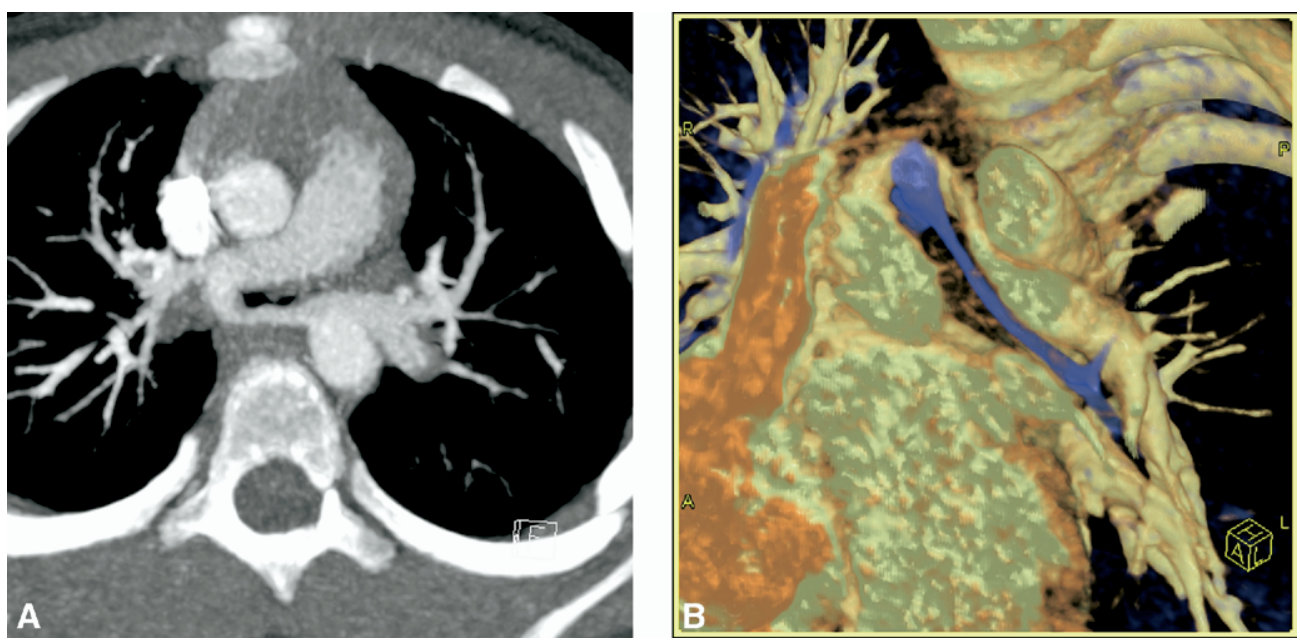

Figure 1. Computed tomographic scan of abnormal left pulmonary artery stretched around trachea. A, Axial view; B, 3-dimensional reconstruction.
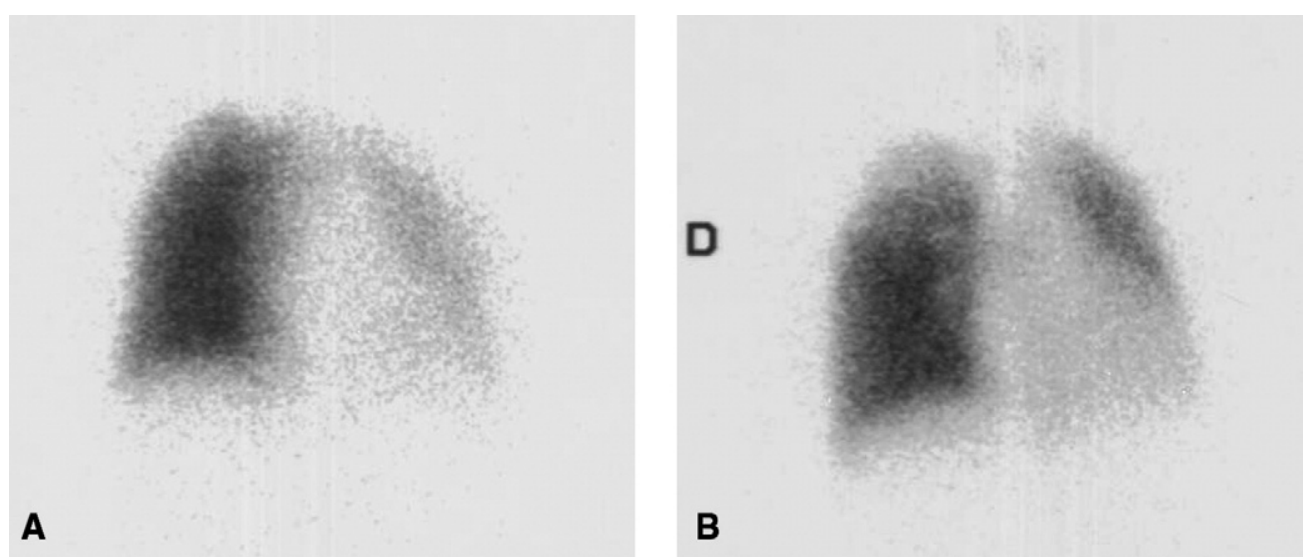

Figure 2. Left lung perfusion (technetium Tc $99 \mathrm{~m}$ ) before (A) and 12 months after (B) surgical correction of pulmonary arterial sling.

the LPA shows an initial segment rightward, then a short segment backward, and at last a long segment leftward, which may have deleterious hemodynamic consequences. Third, the LPA may be stretched around the trachea and the main right bronchus, as observed in our case. For all these reasons, in our opinion, surgical correction of PAS is worthy of consideration, even if the patient has no or mild symptoms. In this 5-year-old child, treatment of the PAS with direct reimplantation caused a significant increase in left lung perfusion after 1 year, even though the echocardiographic estimation of the diameter of the LPA did not change. This finding strongly supports the deleterious hemodynamic consequences of a PAS and constitutes an argument for the surgical correction of this malformation as soon as possible. Indeed, on the basis of recent knowledge regarding lung growth, an even more favorable catch-up effect is suspected in infancy and early childhood. ${ }^{3}$
Conclusion. Surgical correction of PAS may improve lung perfusion. This supports intervention at an early stage, even in symptom-free patients, to promote physiologic lung growth.

\section{References}

1. Berdon WE, Baker DH, Wung JT, Chrispin A, Kozlowski K, de Silva $\mathrm{M}$, et al. Complete cartilage-ring tracheal stenosis associated with anomalous left pulmonary artery: the ring-sling complex. Radiology. 1984;152:57-64.

2. Castaneda AR, Jonas RA, Mayer JE, Hanley FL. Vascular rings, slings, and tracheal anomalies. In: Castaneda AR, Jonas RA, Mayer JE, Hanley FL, editors. Cardiac surgery of the neonate and infant. Philadelphia: WB Saunders; 1994. p. 397-408.

3. Roth-Kleiner M, Post M. Genetic control of lung development. Biol Neonate. 2003;84:83-8. 